of daughters that are good milkers. It is not impossible to aim at 300-400-gallon lactations even among cows of high-class beef type.

The Argentine markets have been responsible for the appearance in sale- and show-rings of a small, thick, fine-quality, fine-boned, short-legged type of animal. This is not necessarily the type desired by the average British farmer, and it is likely that a middle course will be adopted, and that animals will be produced which give reasonable weight for age but are early maturing. Alastair N. Worden.

\section{PLYWOOD ADHESIVES AND LININGS}

$\mathrm{A}$ TTENTION has already been directed in NATURE to the important research work carried out in the Forest Research Institute, Dehra Dun, India, in connexion with the construction of plywood containers to replace metal drums and other containers imported in large quantities before the War, the incidence of the latter bringing this source of supply to an end. In connexion with this research, investigations had to be instituted into possible new adhesives. The Wood Preservation Section of the Institute has done important work on the development of maize and ground-nut proteins as adhesives, and on various lining compounds for proofing plywood containers and drums. The plywood and other industries have been affected by the shortage and high prices of casein, and this work on the protein of maize, which is a waste product of starch manufacture, will not only enable this waste product to be used but also will give an adhesive at a competitive price.

Two Indian Forest Leaflets (Utilization), Nos. 40 and 52 (For. Res. Inst., Dehra Dun, 1943), deal with plywood adhesives. In Leaflet No. 40 (Pp. $\mathrm{ii}+14$. $9 d$.) the result of research has shown that prolamins, isolated from Indian cereals, are equally suitable for the preparation of water-resistant plywood adhesives. This type of adhesive can be prepared by adding to a 20 per cent suspension of prolamin in 80 per cent alcohol, 5 per cent of formaldehyde (40 per cent formalin). One per cent of ammonia or an organic acid such as acetic, tannic, etc., may be added as a catalyst. The adhesive suspension so prepared should be applied within twenty-four hours of its preparation. Veneers coated with these adhesives, after drying at room temperature, should be pressed together at a temperature of $250-300^{\circ} \mathrm{F}$. for a suitable period (10 minutes for $3 / 16$ in. plywood) at a pressure of $200 \mathrm{lb}$. per sq. in.

Leaflet No. 52 (Pp. i $+6.5 d$.) deals with researches with the object of utilizing the wholemeal and proteins of sunn-hemp seed (Crotolaria juncia) for plywood adhesives. For commercial plywood (not requiring a high degree of water resistance) a wholemeal lime silicate formula with rosin, copper sulphate and tannic acid has been found suitable. With the protein, lime silicate and borax-formaldehyde formulæ have been found suitable for the preparation of water-resistant plywood.

Leaflet No. 49 (Pp.ii+10. 5d.) discusses the results of experiments on various types of inner linings suitable for plywood containers for storage of various colmmodities such as greases, liquids and so forth. A variety of inner coatings have been tried and tested; some were found good for certain materials, others for other contents, but a universal leak-proof coating has not yet proved attainable. The requirements demanded by such a lining are nearly as variable as the nature of the commodities themselves. The linings so far tried, nine in number, are : animal glue-treacle composition, prolamin formaldehyde glue, casein or vegetable protein-formaldehyde glue, paraffin wax, bituminous paint, shellac varnish, shellacmelamine composition, phenol-formaldehyde resin and cashew shell oil varnish. The methods of preparation and application of these linings are described in the leaflet.

\section{LOCATING BURIED CABLES ELECTRICALLY}

HOR the protection of buried inter-city cables A against damage by lightning, it is sometimes necessary to install copper shield wires above a cable already in the ground, and the precise route of the cable must be determined so that the shield wires can be correctly placed. It is also important to know the depth of the cable, so that damage to it may be avoided while installing the shield wires. This can now be done electrically with a simple device which consists of coils that pick up a tone which has been applied to the cable sheath. The device is described in an article by R. M. C. Greenidge (Bell Lab. Rec., 22 , No. 3 ; November 1943).

The device carries three coils, a fixed locating coil $A$, a fixed direction coil $B$ and a pivoted depth coil $C$ mounted on a crossbar attached to a vertical rod which supports a graduated quadrant scale $S$ and has a spirit-level on its upper end. A handle is used to adjust the apparatus by forcing a spike into the ground. A selector switch connects any one of the three coils to an amplifier and detector circuit, which is multiple connected to the coil circuits. A pointer $P$ indicates the setting of the depth coil $C$, and a shaft which slides vertically permits levelling the apparatus.

The test current is generated by the buzzer of a $20 \mathrm{C}$. test set. One of its terminals is connected to the cable sheath at a pressure-testing valve and the other to an earth rod located $50-100 \mathrm{ft}$. from the cable. Current flows along the sheath in both directions, and through earth to the earth rod. With the amplifier in operation and earphones used as detector, the selector switch is set to close the locating coil circuit and the apparatus is carried across the path of the cable. When coil $A$ comes directly over the cable, a null position is reached, and at this point the spike is pushed into the ground. By setting the selector switch to close coil $B$ circuit and rotating the apparatus round the spike, the null point of coil $B$ is found. In this position the horizontal bar on which coil $C$ is located is at right angles to the path of the cable. Adjusting the sliding shaft then levels the device, after which the selector switch is set to close coil $C$ circuit and the depth coil rotated on its pivot for the null point. The reading on the scale, as indicated by the pointer, is the distance of the centre of the cable below the surface. If $r$ is the radius of the cable, $h$ the height of the coils above the ground, $l$ the distance between the coils $A$ and $C$, and $d$ the depth of the cable, $d=l \cot \theta-k$, where $k=r+h$ and $\theta$ is the angle which the pointer $P$ makes with the horizontal when coil $C$ is in its null position. By this formula the quadrant scale $S$ can be calibrated for depth.

The depth indicator is usually handled by a team 